\title{
PERENCANAAN PEMBELAJARAN DAN PENGARUHNYA TERHADAP KOMPETENSI GURU PENDIDIKAN AGAMA HINDU
}

\author{
I Putu Widyanto \\ IAHN Tampung Penyang Palangka Raya \\ putuwidyanto@yahoo.co.id
}

\author{
Riwayat Jurnal \\ Artikel diterima: 12 April 2020 \\ Artikel direvisi: 25 April 2020 \\ Artikel disetujui: 29 Juni 2020
}

Kata Kunci:

Perencanaan

pembelajaran

Kompetensi guru

Keyword:
Learning planning
Teacher competence

\section{Abstrak}

Perencanaan pembelajaran merupakan seperangkat rencana dan pengaturan kegiatan pembelajaran, yang berisi tujuan, materi, sarana dan prasarana pembelajaran, pendekatan, strategi serta evaluasi hasil dan proses pembelajaran dijadikan pedoman dalam pembelajaran dalam usaha pencapaian tujuan pembelajaran. Perencanaan pembelajaran yang dibuat guru pendidikan agama Hindu harus komprehensif, sistematis dan mudah diaplikasikan, sehingga pada tahap pelaksanaan pembelajaran guru akan dengan mudah melaksanakan pembelajaran yang sudah direncakan sebelumnya sehingga akan mempengaruhi kinerja guru pendidikan agama Hindu.Tujuan penelitian ini untuk menganalisis bagaimana implementasi perencanaan pembelajaran berpengaruh terhadap kompetensi guru pendidikan agama Hindu. Penelitian ini menggunakan pendekatan penelitian kualitatif dengan jenis penelitian kepustakaan (Library Research). Hasil penelitian menunjukan perencanaan pembelajaran pendidikan agama Hindu sangat penting bagi berjalannya pembelajaran karena sebagai pedoman bagi guru dalam melaksanakan pembelajaran, dengan perencanaan pembelajaran yang baik akan membuat pelaksanaan pembelajaran berjalan baik yang akan berdampak meningkatnya empat kompetensi guru pendidikan agama Hindu meliputi kompetensi pedagogik, kompetensi kepribadian, kompetensi sosial dan kompetensi professional.

\section{Abstract}

Learning planning is a set of plans and arrangements for learning activities, which contain objectives, materials, learning tools and infrastructure, approaches, strategies or evaluation of results and learning processes used as guidelines in learning on the achievement of learning objectives. Learning planning made by 


\begin{tabular}{|l|l|}
\hline $\begin{array}{l}\text { Hindu religious education teachers must be comprehensive, } \\
\text { systematic and easily applied, so that in the implementation phase } \\
\text { of learning the teacher will easily implement the learning that has } \\
\text { been previously planned so that it will affect the performance of } \\
\text { Hindu religious education teachers. The purpose of this study was } \\
\text { to analyze how the implementation of learning planning affects the } \\
\text { competence of Hindu religious education teachers. This study uses } \\
\text { a qualitative research approach to the type of library research } \\
\text { (Library Research). The results showed the planning of Hindu } \\
\text { religious education learning is very important for the course of } \\
\text { learning because as a guide for teachers in implementing learning, } \\
\text { with good learning planning will implement learning run well that } \\
\text { will have an impact on increasing the four competencies of Hindu } \\
\text { religious education teachers including pedagogical competence, } \\
\text { personality competence, social competence, and professional } \\
\text { competence. }\end{array}$ \\
\hline
\end{tabular}

\section{Pendahuluan}

Pembelajaran merupakan interaksi antara guru dan siswa dan sumber belajar sehingga terjadi perubahan yang menyangkut aspek pengetahuan, sikap dan keterampilan (Syarifuddin, 2011: 113-136), yang direncanakan guru untuk memberikan pengalaman belajar dalam rangka mencapaian capaian pembelajaran yang sudah ditetapkan sebelumnya (Rusman, 2017: 85). Pembelajaran yang tepat bagi siswa dapat mengembangkan berpikir kritis, mampu memahami masalah, kreativitas dalam pemecahan masalah dan meningkatkan keterampilan komunikasi dan kerja sama tim (Zakaria \& Awaisu, 2011: 1).

Proses tersebut dapat dicapai melalui penciptaan kondisi pembelajaran yang aktif yang dapat membuat siswa aktif dalam pembelajaran. Penciptaan suasana pembelajaran yang aktif akan membuat respon siswa terhadap interaksi yang dilakukan guru cukup positif, (Wachyudi, Srisudarso, \& Miftakh, 2015: 40-49). Pembelajaran dapat terlaksana secara aktif bila didukung manajemen pembelajaran (Manullang, 2014: 210). Manajemen pembelajaran merupakan pengelolaan pembelajaran untuk mencapai capaian pembelajaran melalui proses interaksi guru dengan siswa dan sumber belajar yang berpedoman pada kurikulum untuk mencapai tujuan pendidikan (Nirwana, 2014: 72). Manajemen pembelajaran dapat berjalan efektif memerlukan fungsi manajemen yang merupakan tahapan bagaimana manajemen pembelajaran berlangsung (Suwito, Harun, \& Ibrahim, 2017: 68). Fungsi manajemen pembelajaran terdiri dari fungsi perencanaan, fungsi pelaksanaan dan fungsi pengawasan (Davies, 2007: 310).

Perencanaan pembelajaran disusun guru sebelum melaksanakan pembelajaran. Perencanaan pembelajaran merupakan seperangkat rencana dan pengaturan kegiatan 
pembelajaran (Maria \& Sediyono, 2017: 60), yang berisi tujuan, materi, sarana dan prasarana pembelajaran, pendekatan, strategi serta evaluasi hasil dan proses pembelajaran dijadikan pedoman dalam pembelajaran dalam usaha pencapaian tujuan pembelajaran (Rayuni, 2010: 77), dan kompetensi tertentu yang telah dirumuskan (Novalita, 2014: 59). Perencanaan pembelajaran yang dibuat guru harus komprehensif, sistematis dan mudah diaplikasikan (Abidin, 2016: 287), sehingga pada tahap pelaksanaan pembelajaran guru akan dengan mudah melaksanakan pembelajaran yang sudah direncakan sebelumnya sehingga akan mempengaruhi kinerja guru.

Perencanaan pembelajaran dapat memberikan manfaat antara lain memudahkan pembuatan persiapan pembelajaran dan memudahkan pengembangan pembelajaran yang aktif, kreatif, efektif dan menyenangkan sehingga akan meningkatkan kompetensi guru (Maria \& Sediyono, 2017: 60). Kompetensi guru merupakan kapasistas seseorang guru untuk mengerjakan berbagai tugas yang menjadi tanggung jawabnya (Yahya \& Hidayati, 2014:107). Seorang guru minimal memilki empat kompetensi yaitu: kompetensi pedagogik, kompetensi profesional, kompetensi sosial dan kompentensi kepribadian (Jurotun, Samsudi, \& Prihatin, 2015:27).

Perencanaan pembelajaran yang baik berdampak terhadap kompetensi guru, hal ini dapat di temui dari hasil penelitian Novalita (2014:61), yang mengungkapkan sebelum pembelajaran dimulai guru harus membuat perencanaan pembelajaran yang bertujuan untuk memudahkan guru dalam melaksanakan pembelajaran sehingga berdampak terhadap kompetensi guru selama pelaksanaan pembelajaran. Penelitian lainnya yang mengungkapkan peran penting perencanaan pembelajaran terhadap kompetensi guru adalah penelitian yang dilakukan Zahroh (2017:143), yang mengungkapkan perencanaan pembelajaran adalah indikator yang dapat dijadikan untuk mengukur kompetensi guru, dimana semakin baik perencanaan yang dibuat menunjukan kompetensi guru tersebut baik.

Pemahaman guru terhadap perencanaan pembelajaran yang baik akan berdampak pada kualitas pembelajaran terlihat pada penelitian diatas, tetapi walaupun mengetahui bahwa perencanaan pembelajaran penting tetapi berdasarkan hasil penelitian (Novalita, 2014:57) ditemukan guru dan mahasiswa praktek mengajar belum mampu merumuskan tujuan pembelajaran, memahami materi pembelajaran, penggunaan metode pembelajaran, penggunaa media pembelajaran, membuka pelajaran, pengelolaan kelas, serta menutup pelajaran. Hal ini disebabkan oleh kurangnya pemahaman dan pengetahuan mahasiswa dalam membuat 
perencanaan pembelajaran serta pentingnya membuat perencanaan pembelajaran yang benar supaya pembelajaran berjalan dengan baik.

Berdasarkan perbedaan hasil penelitian tersebut, diharapkan pengelolaan pembelajaran pendidikan Hindu di tingkat satuan pendidikan sudah harus mulai menerapkan prinsif-prinsif manajemen pembelajaran dengan baik dan dapat dimulai dari perencanaan pembelajaran dengan harapan peningkatan kompetensi guru pendidikan agama Hindu. Sehingga peneliti tertarik untuk melakukan penelitian tentang bagaimana perencanaan pembelajaran dapat mempengaruhi kompetensi guru pendidikan agama Hindu. Tema penelitian tersebut masih jarang dilakukan penelitian dan memiliki peran yang penting dalam meningkatkan kompetensi guru agama Hindu melalui perencanaan pembelajaran. Tujuan penelitian ini untuk menganalisis bagaimana implementasi perencanaan pembelajaran berpengaruh terhadap kompetensi guru pendidikan agama Hindu. Penelitian ini menggunakan pendekatan penelitian kualitatif dengan jenis penelitian kepustakaan (Library Research). Penelitian kepustakaan merupakan kajian teoritis terhadap berbagai referensi serta literatur ilmiah yang berkaitan dengan masalah yang ingin dipecahkan peneliti (T \& Purwoko, 2018:3) yaitu implementasi perencanaan pembelajaran dan pengaruhnya terhadap kinerja guru pendidikan agama Hindu.

\section{Pembahasan}

\section{Perencanaan Pembelajaran Pendidikan Agama Hindu}

Perencanaan pembelajaran merupakan suatu proses yang sistematis dilakukan oleh guru pendidikan agama Hindu dalam membimbing, membantu dan mengarahkan peserta didik untuk memiliki pengalaman belajar serta mencapai tujuan pembelajaran yang telah ditetapkan (Sabirin,2012:117) dengan langkah - langkah penjelasan tujuan, penentuan kebijakan, penentuan program, (Suryapermana, 2017:183), penyusunan materi ajar, penggunaan media, penggunaan pendekatan dan metoda pengajaran, serta penilaian untuk mencapai kompetensi tertentu yang telah dirumuskan (Novalita, 2014:59). Perencanaan pembelajaran dalam bentuk Rencana Program Pembelajaran (RPP) merupakan dokumen wajib yang harus guru pendidikan agama Hindu siapkan sebelum pembelajaran dimulai.

Merumuskan RPP selain berpedoman pada kurikulum dan silabus guru pendidikan agama Hindu juga memperhatikan beberapa hal, antara lain;

1. Capaian Pembelajaran Lulusan.

Pembelajaran yang dirancang guru pendidikan agama Hindu harus mampu memberikan pengalaman belajar yang bermakna kepada siswa untuk membuka keunikan potensi dirinya (Sutrisno \& Suyadi, 2016:110), dengan kegiatan memberikan pengalaman belajar yang 
melibatkan proses mental dan fisik melalui interaksi siswa dengan guru, antar siswa, lingkungan dan sumber belajar untuk mencapaian capaian pembelajaran yang sudah direncanakan yaitu aspek sikap, keterampilan dan pengetahuan (Rusman, 2017:85).

2. Karakteristik Pembelajaran

Pembelajaran yang melibatkan siswa secara aktif selama proses pembelajaran berdampak memberikan pengalaman belajar lebih banyak kepada siswa (Sidek \& Yunus, 2012:135-143). Salah satu pendekatan pembelajaran yang melibatkan siswa secara aktif adalah pendekatan pembelajaran saintifik. Pendekatan saintifik merupakan pendekatan pembelajaran yang digunakan satuan pendidikan pada kurikulum 2013 (Sufairoh, 2016:120). Pembelajaran saintifik merupakan proses pembelajaran yang membuat peran siswa menjadi aktif, dimana selama pembelajaran siswa mengkonstruksi konsep melalui tahapan mengamati, menanya, ngumpulkan informasi, mengolah data atau menganalisis data, menarik kesimpulan dan mengkomunikasikan (Deden, 2015:100). Pendekatan saintifik mengajak siswa untuk melakukan proses pencarian pengetahuan berkenaan dengan materi pelajaran melalui berbagai aktivitas dalam melakukan penyelidikan ilmiah untuk menemukan sendiri berbagai fakta, membangun konsep dan nilai-nilai baru yang diperlukan (Ine, 2015:271).

3. Metode Pembelajaran.

Penggunaan metode yang tidak sesuai dengan capaian pembelajaran yang sudah dirancang dapat menjadi kendala dalam mencapai tujuan, oleh karena itu pemahaman guru pendidikan agama Hindu dalam memilih metode pembelajaran sangat penting sebelum memutuskan metode mana yang akan dipakai (Samiudin, 2016:119), karena keberhasilan pembelajaran tergantung dari metode pembelajaran yang digunakan (Kartiani, 2015:213).

4. Prinsip penilaian.

Penilaian seharusnya berorientasi pada ketercapaian dan proses pembelajaran, bukan benar atau salah artinya, penilaian masih bisa berubah jika siswa bersedia memperbaiki proses. Kondisi akan dapat dilakukan bila sistem penilaian menggunakan sistem penilaian otentik (Sutrisno \& Suyadi, 2016:162). Penilaian otentik adalah pengukuran yang bermakna secara signifikan untuk ranah sikap, keterampilan, dan pengetahuan. Prinsip penilaian otentik dalam pembelajaran tidak hanya menilai apa saja yang sudah diketahui oleh siswa, tetapi juga menilai proses selama pembelajaran maupun setelah pembelajaran selesai, sehingga kualitas hasil belajar dan kerja siswa dalam menyelesaikan tugas dapat terukur (Ani, 2013:747). 
Setelah membuat RPP guru pendidikan agama Hindu wajib membuat perangkat pembelajaran berupa materi pembelajaran. Pembelajaran dapat berjalan efektif bila didukung oleh beberapa faktor yaitu kurikulum, guru, metode, sarana dan prasarana dan siswa (Ladjid, 2005:113). Sedangkan untuk mempermudah, guru dan siswa dalam pelaksanaan pembelajaran membutuhkan materi pembelajaran yang menjadi acuan bagi guru (Soemohadiwidjojo, 2014:87). Materi pembelajaran yang digunakan untuk membantu guru dan siswa sebagai pedoman pembelajaran harus memiliki sifat kepraktisan dan efektivitas.

Perencanaan pembelajaran sangat penting bagi berjalannya pembelajaran karena sebagai pemandu bagi guru pendidikan agama Hindu dalam melaksanakan pembelajaran, oleh sebab itu perencanaan haruslah lengkap, sistematis mudah diaplikasikan namun fleksibel dalam penerapannya (Abidin, 2016:287), serta dapat menjadi pedoman dalam usaha pencapaian tujuan (Rayuni, 2010:77), karena dengan perencanaan pembelajaran yang baik akan membuat pelaksanaan pembelajaran berjalan baik (Amanaturrakhmah, Kardoyo, \& Rifai, 2017:164).

\section{Pengaruh Perencanaan Pembelajaran Terhadap Kompetensi Guru Pendidikan Agama} Hindu

Kompetensi guru pendidikan agama Hindu merupakan kemampuan seorang guru pendidikan agama Hindu dalam melaksanakan kewajibannya yang dikembangkan secara utuh dalam empat kompetensi meliputi kompetensi pedagogik, kompetensi kepribadian, kompetensi sosial dan kompetensi professional. Kondisi ini menunjukan guru pendidikan agama Hindu tidak hanya menyampaikan materi tetapi mengembangkan kompetensi lainnya (Nurtanto, 2013:553).

Kompetensi pedagogik adalah kemampuan guru mengelola pembelajaran meliputi, perancangan, pelaksanaan pembelajaran dan evaluasi hasil belajar dan pemahaman dan pengembangan siswa berdasarkan potensi yang dimilikinya (Balqis, Usman, \& Ibrahim, 2014:27). Dengan melakukan perencanaan pembelajaran guru pendidikan agama Hindu dapat melakukan proses penyusunan materi ajar, penggunaan media yang akan digunakan, pemilihan penggunaan pendekatan dan metoda pengajaran, serta format penilaian dalam suatu alokasi waktu untuk mencapai kompetensi tertentu yang telah dirumuskan (Novalita, 2014:59). Dengan melakukan kegiatan perencanaan guru pendidikan agama Hindu dapat melakukan berbagai persiapan sehingga pada tahap pelaksanaan pembelajaran dan tahapan evaluasi dapat berjalan baik sehingga dapat meningkatkan kompetensi pedagogik guru pendidikan agama Hindu.

Kompetensi kepribadian ialah karakteristik pribadi seorang guru yang harus dimiliki sebagai individu yang mantap, stabil, dewasa, arif dan berwibawa, serta menjadi teladan bagi 
siswanya (Suatrean \& Jusriana, 2016:77). Kepribadian guru sangat ditentukan bagaimana guru pendidikan agama Hindu mendidik dan membina siswa agar mampu mengembangkan potensi yang dimilikinya (Purwanti, 2013:1075) berdasarkan pendidiakn agama Hindu. Pemahaman siswa terhadap materi sangat bervariasi mulai anak itu cepat memahami materi dan lambat dalam memahami materi, oleh karena itu peran guru pendidikan agama Hindu sangat penting untuk mendidik dan membina siswa yang menghadapi masalah dalam belajar (Ramona, Melia, \& Harisnawati, 2017:3). Guru pendidikan agama Hindu sangat di tuntut untuk mampu menghadirkan pengalaman belajar yang dapat memberikan kemudahan penguasaan capaian pembelajaran, untuk itu proses perencanaan pembelajaran menjadi sangat penting karena guru pendidikan agama Hindu sudah dapat mulai merancang pengalaman belajar yang seperti apa yang di dapatkan siswa dan bagaimana proses pembelajarannya berlangsung sehingga dengan perencanaan yang baik akan meningkatkan kompetensi kepribadian guru pendidikan agama Hindu yang mempu mendidik dan membimbing siswa untuk mengembangkan potensinya.

Proses pembelajaran tidak akan berjalan dengan baik apabila guru pendidikan agama Hindu tidak mampu berkomunikasi menghadirkan suasana pembelajaran yang kondusif. Oleh karena itu, guru pendidikan agama Hindu haruslah memiliki kemampuan sosial atau kompetensi sosial dalam berkomunikasi dengan siswa, tenaga kependidikan, orang tua siswa dan masyarakat. (Erlinda, 2017:391). Selama proses perencanaan pembelajaran guru pendidikan agama Hindu dapat mengagendakan pertemuan dengan guru lain maupun orang tua/wali siswa untuk mengkomunikasikan kemajuan proses pembelajaran siswa dan perkembangan sekolah. Selain itu menghadirkan interaksi pembelajaran yang aktif yang membuat komunikasi guru pendidikan agama Hindu dan siswa terjalin sangat ditentukan oleh bagaimana guru pendidikan agama Hindu merencanakan pendekatan pembelajaran yang akan digunakan. Dengan kemampuan komunikasi yang baik diharapkan segala macam hambatan yang akan atau dapat ditimbulkan selama proses pembelajaran dapat dihilangkan. Kedekatan yang terjalin dengan baik antara guru dan siswa akan memberikan dampak positif bagi perkembangan belajar siswa.

Profesionalisme guru merupakan suatu kebutuhan utama, untuk menghadapi era revolusi industri 4.0., dengan kapasitas yang dimilikinya agar dapat berperan secara maksimal untuk mengembangkan dan meningkatkan kualitas pembelajaran (Yusutria, 2017:40). Untuk menjadi guru yang profesional, guru pendidikan agama Hindu harus berotoritasi mutu dan beretos kerja tinggi dan menjadikannya sebagai landasan orientasi berperilaku dalam tugas-tugasnya 
profesinya (Nurtanto, 2013:554) Ditangan guru pendidikan agama Hindu yang profesional pembelajaran agama Hindu menjadi aktif dengan memperdayakan sarana dan prasarana lebih maksimal (Kalu, Rede, \& Asep, 2016:85). Membuat peerencanaan pembelajaran merupakan langkah pertama guru pendidikan agama Hindu agar pembelajaran berjalan sesuai dengan yang diharapkan, kondisi ini menunjukan guru pendidikan agama Hindu telah profesional (Febrina, Hajidin, \& Mahmud, 2016:46). Guru pendidikan agama Hindu wajib membuat perencanaan pembelajaran yang baik dimana di mulai dari membuat Rencana Pelaksanaan Pembelajaran (RPP) (Hanifa, 2017:196). Berdasarkan RPP inilah guru pendidikan agama Hindu dapat menerapkan pembelajaran dengan terprogram. RPP mempunyai fungsi perencanaan dan fungsi pelaksanaan, sebagai fungsi perencanaan membuat guru melaksanakan pembelajaran dengan perencanaan yang matang dan dalam pelaksanaan, RPP mengefektifkan proses pembelajaran sesuai dengan apa yang direncanakan (Sholeh, 2007:136).

\section{Simpulan}

Perencanaan pembelajaran sangat penting bagi berjalannya pembelajaran karena sebagai pedoman bagi guru pendidikan agama Hindu dalam melaksanakan pembelajaran, karena dengan perencanaan pembelajaran yang baik akan membuat pelaksanaan pembelajaran berjalan baik yang akan berdampak meningkatnya empat kompetensi guru pendidikan agama Hindu meliputi kompetensi pedagogik, kompetensi kepribadian, kompetensi sosial dan kompetensi professional.

Pengaruh perencanaan pembelajaran terhadap kompetensi pedagogik guru pendidikan agama Hindu yaitu dengan melaksanakan perencanaan pembelajaran yang tepat guru pendidikan agama Hindu dapat melakukan berbagai persiapan sehingga pada tahap pelaksanaan pembelajaran dan tahapan evaluasi dapat berjalan baik sehingga dapat meningkatkan kompetensi pedagogik guru pendidikan agama Hindu.

Pengaruh perencanaan pembelajaran terhadap kompetensi kepribadian yaitu guru pendidikan agama Hindu sangat di tuntut untuk mampu menghadirkan pengalaman belajar yang dapat memberikan kemudahan penguasaan capaian pembelajaran, untuk itu proses perencanaan pembelajaran menjadi sangat penting karena guru pendidikan agama Hindu sudah dapat mulai merancang pengalaman belajar yang seperti apa yang di dapatkan siswa dan bagaimana proses pembelajarannya berlangsung sehingga dengan perencanaan yang baik akan meningkatkan kompetensi kepribadian guru pendidikan agama Hindu yang mempu mendidik dan membimbing siswa untuk mengembangkan potensinya. 
Pengaruh perencanaan pembelajaran terhadap kompetensi sosial guru pendidikan agama Hindu yaitu selama proses perencanaan pembelajaran guru pendidikan agama Hindu dapat mengagendakan pertemuan dengan guru lain maupun orang tua/wali siswa untuk mengkomunikasikan kemajuan proses pembelajaran siswa dan perkembangan sekolah. Selain itu menghadirkan interaksi pembelajaran yang aktif yang membuat komunikasi guru pendidikan agama Hindu dan siswa terjalin sangat ditentukan oleh bagaimana guru merencanakan pendekatan pembelajaran yang akan digunakan. Dengan kemampuan komunikasi yang baik diharapkan segala macam hambatan yang akan atau dapat ditimbulkan selama proses pembelajaran dapat dihilangkan. Kedekatan yang terjalin dengan baik antara guru dan siswa akan memberikan dampak positif bagi perkembangan belajar siswa.

Pengaruh perencanaan pembelajaran terhadap kompetensi profesional yaitu membuat peerencanaan pembelajaran merupakan langkah pertama guru pendidikan agama Hindu agar pembelajaran berjalan sesuai dengan yang diharapkan, kondisi ini menunjukan guru pendidikan agama Hindu telah profesional. Berdasarkan perencanaan dalam bentuk RPP, guru pendidikan agama Hindu dapat menerapkan pembelajaran dengan terprogram. RPP mempunyai fungsi perencanaan dan fungsi pelaksanaan, sebagai fungsi perencanaan membuat guru melaksanakan pembelajaran dengan perencanaan yang matang dan dalam pelaksanaan, RPP mengefektifkan proses pembelajaran sesuai dengan apa yang direncanakan.

\section{Daftar Pustaka}

Abidin, Y. (2016). Desain Sistem Pembelajaran dalam Konteks Kurikulum 2013. Rafika Aditama.

Amanaturrakhmah, I., Kardoyo, \& Rifai, A. (2017). Manajemen Pembelajaran Tematik di Kelas Tinggi SD Percontohan Kabupaten Indramayu. Journal of Primary Education, 6(2), 159-165. https://doi.org/10.15294/JPE.V6I2.17570

ANI, Y. (2013). Penilaian autentik dalam kurikulum 2013. Seminar Nasional Implementasi Kurikulum 2013, 742-749.

Balqis, P., Usman, N., \& Ibrahim, S. (2014). Kompetensi Pedagogik Guru Dalam Meningkatkan Motivasi Belajar Siswa Pada SMPN 3 Ingin Jaya Kabupaten Aceh Besar. Jurnal Administrasi Pendidikan Pascasarjana Universitas Syiah Kuala, 2(1), 25-38.

Davies, E. (2007). The Training Manager's Desktop Guide. In Journal of Experimental Psychology: General (Vol. 136, Issue 1). Thorogood Publishing Ltd.

Deden. (2015). Penerapan Pendekatan Saintifik Dengan Menggunakan Model Pembelajaran Inkuiri Pada Mata Pelajaran Ekonomi. Prosiding Seminar Nasional 9 Mei 2015, 98-107. 
http://eprints.uny.ac.id/21691/1/11 Deden.pdf

Erlinda, N. (2017). Karakteristik guru yang memiliki kompetensi sosial. Prosiding Seminar Nasional Tahunan Fakultas Ilmu Sosial Universitas Negeri Medan, 391-394.

Febrina, F., Hajidin, \& Mahmud. (2016). Kompetensi Guru Dalam Perencanaan Pembelajaran Di SDN 2 Banda Aceh. Jurnal Ilmiah Mahasiswa Prodi PGSD, 1(1), 4050 .

Hanifa. (2017). Meningkatkan Kemampuan Guru dalam Menyusun Perencanaan Pembelajaran Melalui Pembinaan Kolaboratif Bagi Guru Kelas V di Dabin II Unit Pendidikan Kecamatan Gedangan. PEDAGOGIA : Jurnal Pendidikan, 6(2), 194-211.

Ine, M. E. (2015). Penerapan Pendekatan Scientific Untukmeningkatkan Prestasi Belajar Siswa Padamata Pelajaran Ekonomi Pokok Bahasan Pasar. Prosiding Seminar Nasional 9 Mei 2015, 20, 269-285.

Jurotun, Samsudi, \& Prihatin, T. (2015). Model Supervisi Akademik Terpadu Berbasis Pemberdayaan MGMP untuk Meningkatkan Kompetensi Pedagogik Guru Matematika. Jurnal Penelitian Tindakan Sekolah Dan Kepengawasan, 2(1), 27-34.

Kalu, M. R., Rede, A., \& Asep, H. (2016). Kompetensi Pedagogik Dan Profesional Guru Sekolah Dasar Yang Tersertifikasi Pada Pembelajaran Sains. Jurnal Sains Dan Teknologi Tadulako, 5(3), 85-94.

Kartiani, B. S. (2015). Pengaruh Metode Pembelajaran Dan Motivasi Belajar Terhadap Hasil Belajar Siswa Pada Mata Pelajaran IPS Kelas V Kabupaten Lombok Barat NTB. Jurnal Pendidikan Dasar, 6(2), 212-221.

Ladjid, H. (2005). Pengembangan Kurikulum Menuju Kurikulum Berbasis Kompetensi. Quantum Teaching.

Manullang, M. (2014). Manajemen Pembelajaran Matematika. Jurnal Pendidikan Dan Pembelajaran, 21(2), 208-214. http://journal.um.ac.id/index.php/pendidikan-danpembelajaran/article/view/7532/3445

Maria, E., \& Sediyono, E. (2017). Pengembangan Model Manajemen Pembelajaran Berbasis TIK Di Sekolah Dasar. Jurnal Kelola UKSW, 4(1), 59-71.

Nirwana. (2014). Pengaruh Manajemen Pembelajaran Berbasis Lingkungan Dan Gaya Kognitif Terhadap Hasil Belajar IPA-Fisika Di SMPN Kota Bengkulu (Studi eksperimen pada Siswa Kelas VII Semester I SMPN 11 Kota Bengkulu) 2012. Prosiding Seminar Nasional Fisika (E-JOURNAL) SNF2014, 3, 71-79.

Novalita, R. (2014). Pengaruh Perencanaan Pembelajaran Terhadap Pelaksanaan Pembelajaran (Suatu Penelitian terhadap Mahasiswa PPLK Program Studi Pendidikan Geografi FKIP Universitas Almuslim). Lentera, 14(2), 56-61. http://jurnal.umuslim.ac.id/index.php/LTR1/article/download/201/124

Nurtanto, M. (2013). Mengembangkan Kompetensi Profesionalisme Guru Dalam Menyiapkan Pembelajaran Yang Bermutu. Seminar Nasional Inovasi Pendidikan, 10, 553-565.

Purwanti. (2013). Guru dan kompetensi kepribadian. Jurnal Visi Ilmu Pendidikan, 10(1), 1074-1088.

Ramona, Melia, Y., \& Harisnawati. (2017). Strategi guru menghadapi siswa slow learning dan speed learning dalam proses pembelajaran sosiologi di sma negeri 4 pariaman. Jurnal Ilmiah Mahasiswa STKIP PGRI Sumbar. 
Rayuni, D. (2010). Manajemen Pembelajaran Di Madrasah Aliyah Negeri ( MAN ) 3 Palembang. TA'DIB, $X V(1)$.

http://jurnal.radenfatah.ac.id/index.php/tadib/article/view/68

Rusman. (2017). Belajar \& Pembelajaran Berorientasi Standar Proses Pendidikan. Kencana.

Sabirin. (2012). Perencanaan Kepala Sekolah Tentang Pembelajaran. Jurnal Tabularasa PPS UNIMED, 9(1), 111-128.

Samiudin. (2016). Peran metode untuk mencapai tujuan pembelajaran. Jurnal Studi Islam, 11(2), 94-97. https://jurnal.yudharta.ac.id/v2/index.php/pai/article/view/407

Sholeh, M. (2007). Perencanaan Pembelajaran Mata Pelajaran Geografi Tingkat SMA Dalam Konteks KTSP. Jurnal Geografi, 4(2), 129-137.

Sidek, E. A. R., \& Yunus, M. M. (2012). Students' Experiences on using Blog as Learning Journals. Procedia - Social and Behavioral Sciences, 67(November 2011), 135-143. https://doi.org/10.1016/j.sbspro.2012.11.314

Soemohadiwidjojo, A. T. (2014). Mudah Menyusun SOP. Penebar Plus.

Suatrean, R. A., \& Jusriana, A. (2016). Hubungan Kompetensi Kepribadian Dengan Kompetensi Pedagogik Guru Fisika Madrasah Aliyah Kota Makassar. Jurnal Pendidikan Fisika, 4(2), 75-82.

Sufairoh. (2016). Pendekatan Saintifik \& Model Pembelajaran K-13. Jurnal Pendidikan Profesional, 5(3). https://doi.org/10.26555/bahastra.v37i1.5641

Suryapermana, N. (2017). Manajemen Perencanaan Pembelajaran. Tarbawi, 3(02), 183-193. https://www.neliti.com/publications/256452/manajemen-perencanaan-pembelajaran

Sutrisno, \& Suyadi. (2016). Desain Kurikulum Perguruan tinggi, Mengacu KKNI. PT Remaja Rosdakarya.

Suwito, Harun, C. Z., \& Ibrahim, S. (2017). Manajemen Pembelajaran Bahasa Inggris Dalam Meningkatkan Prestasi Belajar Siswa Pada SMP NEGERI 1 TAPAKTUAN ACEH. Jurnal Magister Administrasi Pendidikan PascasarjanaUniversitasSyiah Kuala, 5(3), $67-73$.

Syarifuddin, A. (2011). Penerapan Model Pembelajaran Cooperative Belajar Dan FaktorFaktor Yang Mempengaruhinya. Ta'dib; Vol 16, No 01 (2011), 113-136. http://jurnal.radenfatah.ac.id/index.php/tadib/article/view/57/52

T, A. M., \& Purwoko, B. (2018). Studi Kepustakaan Mengenai Landasan Teori Dan Praktik Konseling Expressive Writing. Jurnal BK UNESA, 8(1), 1-8. https://jurnalmahasiswa.unesa.ac.id/index.php/jurnal-bk-unesa/article/view/22037

Wachyudi, K., Srisudarso, M., \& Miftakh, F. (2015). Analisis Pengelolaan dan Interaksi Kelas dalam Pengajaran Bahasa Inggris. Jurnal Ilmiah Solusi, 1(4), 40-49. https://doi.org/10.1017/CBO9781107415324.004

Yahya, Z., \& Hidayati, F. (2014). Analisis Kompetensi Terhadap Penilaian Kinerja Dosen (Studi Kasus Dosen Uin Sultan Syarif Kasim Riau). Jurnal Penelitian Sosial Keagamaan, 17(1), 104-126.

Yusutria. (2017). Profesionalisme Guru Dalammeningkatkan Kualitas Sumberdaya Manusia. Jurnal Curricula, 2(1), 38-46. 
Zahroh, M. N. (2017). Evaluasi Kinerja Guru Dalam Peningkatan Mutu Pendidikan Di Yayasan Al Kenaniyah Jakarta Timur. Jurnal Manajemen Pendidikan, 8(1), 139. https://doi.org/10.21009/jmp.08113

Zakaria, S. F., \& Awaisu, A. (2011). Shared-Learning Experience During a Clinical Pharmacy Practice Experience. American Journal of Pharmaceutical Education, 75(4), 75. https://doi.org/10.5688/ajpe75475 